\title{
Estado de exceção como paradigma para o Direito Internacional
}

\author{
Henrique Weil Afonso \\ henrique_weil@yahoo.com.br \\ Graduado em Direito pela Universidade Federal de Juiz de \\ Fora. Estudante visitante do Colorado College (EUA, 2005) e \\ da University of Westminster (Inglaterra, 2007). Mestrando em \\ Direito Público Internacional na Pontifícia Universidade Católica.

\section{José Luiz Quadros de Magalhães} \\ ceede@uol.com.br \\ Doutor, Mestre e Especialista em Direito Público e Constitucional \\ pela Universidade Federal de Minas Gerais, professor dos \\ cursos de pós-graduação (mestrado e doutorado) da Pontifícia \\ Universidade Católica de Minas Gerais; Universidade Federal de \\ Minas Gerais; UNIPAC - Universidade Presidente Antonio Carlos \\ - Juiz de Fora - MG; e Universidade de Buenos Aires, Argentina. \\ Recebimento do artigo: 15/09/2009 \\ Aprovado em: 10/12/2009
}

\section{Resumo}

A emergência do Estado de Exceção como paradigma de governo repercute no modo como o Direito Internacional regula o uso da força pelos Estados. As graves violações de direitos humanos conduzidas por governos em face de seus próprios cidadãos pressionam a sociedade internacional a agir em defesa destes direitos universais. Por um lado, a prevalência dos Estados como os mais importantes sujeitos no plano jurídico internacional; a atual configuração do Conselho de Segurança; e a positivação dos princípios da soberania e nãointervenção conferem aos governos autonomia na condução dos seus atos. Igualmente, a ênfase na defesa dos interesses nacionais enfraquece as iniciativas de cooperação entre os Estados. Por outro lado, o comprometimento com a promoção e defesa dos Direitos Humanos exige do Direito Internacional a superação de tais dogmas: a valorização do ser humano enquanto sujeito de direitos e a progressiva construção de uma consciência internacional em torno das barbaridades perpetradas contra os Direitos Humanos por governos podem traçar novos rumos para o Direito Internacional.

\section{Palavras-chave}

Estado de Exceção. Intervenção Humanitária. 


\title{
The State of Exception as a paradigm to International Law
}

\author{
Henrique Weil Afonso
}

\author{
José Luiz Quadros de Magalhães
}

\section{Abstract}

The emergence o the State of Exception as a government paradigm reverberates on how the use of force is regulated by International Law. Major buman rights violations conducted by governments in face of their own citizens who pressures international society to act in defense of such rights. On the one hand, the prevalence of States as the most important actors in the international legal realm; the current configuration of the Security Council; and the dogmatization of the sovereign and non-intervention principles given to the governments the autonomy to conduct their own businesses. Likewise, the emphasis in the defense of national interests weakens cooperation initiatives among States. On the other hand, the commitment with the promotion and defense of Human Rights requires International Law to overcome these dogmas: praising human beings as subjects of rights and the progressive construction of an international conscience on the atrocities perpetrated against Human Rights by governments insert new paths to International Law.

\section{Key words}

State of exception. Humanitarian intervention. 


\section{Sumário}

Introdução.

1 O Estado-moderno e as fundações do Direito Internacional.

2 A Intervenção Humanitária e o paradigma do Estado de Exceção.

Conclusão.

Referências Bibliográficas.

\section{Introdução}

A ordem jurídica internacional carece de uma definição precisa. O recurso à analogia com o ordenamento jurídico estatal não se mostra apto à tarefa de descrever o funcionamento do Direito Internacional: por um lado, a ausência de um autêntico Leviatã capaz de impor a força da lei aos Estados-nação, e por outro, as peculiaridades de um contexto histórico marcado pelo fenômeno da globalização são elementos que dificultam a caracterização da ordem jurídica internacional.

De fato, os tradicionais conceitos propostos por importantes juristas ${ }^{1}$ tendem a ser rotulados como demasiados simplistas, uma vez que não contemplam a vasta gama de desafios, ideologias e dificuldades que permeiam nosso tempo. A própria unidade do ordenamento jurídico internacional vem sendo contestada por diver-

1 De acordo com HART, H.L.A. The concept of law. Oxford: Clarendon Press, 1961 o Direito seria composto por normas primárias e secundárias. As regras primárias são aquelas que normatizam as ações dos indivíduos, ao passo que as normas secundárias tratam da criação, alteração e eliminação das regras primárias do sistema jurídico. Cumpre destacarmos, dentre as espécies de regras secundárias, a chamada "regra de reconhecimento", que deve ser entendida como a regra basilar do sistema normativo e que lhe confere sustentação. A ordem jurídica, conforme propõe a clássica obra de Hans KELSEN Teoria pura do direito. trad. São Paulo: Martins Fontes, 2006 conta como característica fundamental o fato de ser uma ordem coercitiva. Nesse sentido, se há coação, há Direito; o Direito Internacional seria, seguindo este entendimento, uma ordem jurídica dotada de coação e que se encontra em estágio de evolução inicial, uma vez que se encontram presentes os elementos normativos mínimos e essenciais. 
sos internacionalistas, que vislumbram o chamado fenômeno da fragmentação ${ }^{2}$ do Direito Internacional.

A regulação do uso da força armada pelos Estados e as peculiaridades da sociedade internacional contemporânea imprimem novos rumos ao Direito Internacional, que se pretende promotor dos Direitos Humanos. Em um primeiro momento, o presente estudo propõe analisar o surgimento do Estado moderno e suas repercussões na formação do Direito Internacional. Em seguida, a atual normatização do recurso ao uso da força armada por parte dos Estados é inserida em um contexto de promoção dos Direitos Humanos no plano supra-nacional. O fortalecimento do Estado de Exceção, assim como a necessidade de resposta pela sociedade internacional diante das graves violações de direitos humanos perpetradas por governos aos seus próprios cidadãos consiste na máxima expressão deste crescente paradigma de governo, exigindo da sociedade internacional uma resposta.

$\overline{2}$ A este respeito - e tendo em vista que este instigante tema não é objeto deste trabalho - remetemos a estudo nosso: "A fragmentação do Direito Internacional se desenvolve em três níveis. No primeiro nível observa-se que a hermenêutica do Direito Internacional passa a ser realizada por diferentes sujeitos, de forma a ampliar as possibilidades interpretativas e contribuindo para o desfazimento de sua unidade. Ao lado dos Estados, podemos vislumbrar as organizações internacionais e indivíduos usufruindo de direitos e incorporando certos deveres para com a ordem jurídica transnacional. Já em um segundo nível constata-se a criação de novos regimes "às margens" das normas de Direito Internacional geral, isto é, regimes que repudiam a estrita obediência ao texto legal, preconizando a realização dos objetivos mais específicos." AFONSO, Henrique Weil. Unidade e fragmentação do direito internacional: o papel dos direitos humanos como elemento unificador. Revista Eletrônica de Direito Internacional, v. 4, p. 53-90, 2009, p. 9 Remetemos aos seguintes estudos para aprofundamento no tema: KOSKENNIEMI, Martti. Global legal pluralism: multiple regimes and multiple modes of thought. Harvard, 05 de março de 2005 - Palestra. Disponível em <http://www.helsinki. fi/eci/Publications/Talks_Papers_MK.htm>. Acesso em: 05 maio 2008; BURKE-WHITE, William W. International legal pluralism. Michigan Journal of International Law, Vol. 25, p. 963-979, 2004; PAUWELYN, Joost. Bridging fragmentation and unity: international law as a universe of inter-connected islands. Michigan Journal of International Law, Vol. 25, p. $903-$ 916, 2004. 


\section{O Estado-moderno e as fundações do Direito Internacional}

O contexto histórico do surgimento e fortalecimento do Estado-nação ${ }^{3}{ }^{4}$ moderno marca a gênese do Direito Internacional: este surgiu com o objetivo primeiro de coordenar as relações entre os Estados, que em meados do século XVII eram por excelência os únicos sujeitos de Direito Internacional. ${ }^{5}$

O Estado nacional moderno somente foi possível com o desenvolvimento do conceito da soberania estatal, ${ }^{6}$ conceito este que se desdobra nos níveis interno e externo. Em nível interno, a soberania estatal representa a instituição de uma ordem jurídica chefiada pelo Estado, que por sua vez detém o monopólio do uso da força. Em nível externo, implica na existência de um Estado de Natureza no qual “(...) a liberdade do Estado é a mesma que teria cada homem, se não houvesse leis civis e nem mesmo Estado. (...) existe uma guerra perpétua... entre os Estados independentes". 7 Princípio basilar do Direito Internacional, a soberania estatal representa

\footnotetext{
A construção do Estado-nação como ente abstrato deu-se de forma desigual ao redor do mundo, tendo sua consolidação ocorrida primeiramente na Europa - Portugal, Espanha, França e Inglaterra em especial - a partir do domínio do poder do Rei sobre os senhores feudais, para em seguida afirmar-se perante o poder do Império e da Igreja do século XVII. A partir do seu estabelecimento no Velho Continente, os movimentos colonialistas levados a cabo pelas principais potências se encarregaram de propagar o Estado em nível internacional. A unificação do exército, da moeda, do Direito, da cultura e a criação de uma nacionalidade única em seu interior foram essenciais à afirmação do Estado como ente abstrato, separado das figuras dos governantes CREVELD, Martin Van. Ascensão e declínio do Estado. São Paulo: Martins Fontes, 2004.

4 A busca por uma uniformização de modos de vida é a essência do Estado: "Portanto, a tarefa de construção do Estado nacional (do Estado moderno) dependia da construção de uma identidade nacional ou, em outras palavras, da imposição de valores comuns que deveriam ser compartilhados pelos diversos grupos étnicos, pelos diversos grupos sociais para que assim todos reconhecessem o poder do Estado. [...] A formação do Estado moderno está, portanto, intimamente relacionada com a intolerância religiosa, cultural, a negação da diversidade fora de determinados padrões e limites.” MAGALHÃES, José Luiz Quadros de. Identidades e identificações de possibilidade de construção de uma ética universal. Veredas do Direito, vol. 5, número 9/10. janeiro dezembro de 2008, p. 47.

5 ROSENNE, SH. "Recueil des Cours". Tome 291 de La collection The Hague. Martines Nijhoff Publishers, 2002. CREVELD, Martin Van. Ascensão e declínio do Estado. São Paulo: Martins Fontes, 2004.

6 Este conceito se desenvolve a partir da ideia de communitas orbis (comunidade mundial) vislumbrada pelo internacionalista Francisco de Vitoria (séc. XVI), para em um momento posterior vir a se consolidar nas obras de Hugo Grotius, Jean Bodin, Thomas Hobbes e John Locke FERRAJOLI, Luigi. A soberania do mundo moderno. Trad. São Paulo: Martins Fontes, 2007.

7 HOBBES, apud FERRAJOLI, Luigi. A soberania do mundo moderno. São Paulo: Martins Fontes, 2007
} 
A superação do estado de natureza, internamente, e a sua conservação (ou melhor, instauração), externamente, tornam-se, assim, as duas coordenadas ao longo das quais se desenrola a história teórica e prática dos Estados soberanos modernos, ambas inscritas no código genético de tais Estados pela filosofia política jusnaturalista. Disso resulta um Estado moderno como sujeito soberano, que é fundado, laica e racionalmente, sobre duas oposições - por negação e por afirmação - ao estado de natureza: sobre a negação, enquanto 'estado civil', do 'estado de natureza' originário das sociedades primitivas e selvagens dos homens de carne e osso e, portanto, sobre a oposição entre 'civilidade' e 'incivilidade', como fonte de legitimação de novas formas de desigualdade e domínio; e, como corolário, sobre a afirmação de um novo estado de natureza paradoxalmente artificial porque produzido pelo mesmo artifício do qual nasce o Estado: a sociedade selvagem, mas artificial, dos Estados soberanos, virtualmente em estado de guerra entre si, mas também coligados, como 'mundo civil', pelo direito-dever de civilizar o resto do mundo ainda não civilizado. ${ }^{8}$

A partir da noção de soberania visualiza-se outro importante marco teórico para o plano jurídico internacional: a ideia de igualdade soberana ${ }^{9}$ entre os Estados. Atribuise a Emmerich de Vattel $^{10}$ (século XVIII) a formulação do princípio da igualdade soberana estatal, ${ }^{11}$ de modo que a ampla aceitação de sua formulação pelos Estados republicanos do século XVIII foi essencial para o projeto de enfraquecimento do poder monárquico e consequente consolidação do Estado-nação moderno. O princípio da não-intervenção em assuntos internos dos Estados seria, nesse diapasão, desdobramento e corolário da igualdade soberana entre os Estados.

Com efeito, o Direito Internacional consolida-se, assim, já no século XIX e início do século XX, como o Direito dos Estados. O direito de recurso à força militar para resolução de disputas entre os Estados foi então elevado a condição sine qua non do exercício do poder soberano em nível externo, onde prevalecia de forma incontestável a doutrina do realismo político ${ }^{12}$ das relações internacionais. A guerra

8 FERRAJOLI, Luigi. A soberania do mundo moderno. São Paulo: Martins Fontes, 2007, p. 25. Grifo nosso.

9 O Artigo 2 (1) da Carta da ONU codifica o princípio: "A Organização é baseada na igualdade de todos os seus membros."

10 Apud LEE, Thomas H. International Law, International Relations Theory and Preemptive War: The Vitaly of Sovereingns Equality Today". Law and Contemporary Problems, volume 67, n. 4, 2004, p. 150. "Um anão é tão homem quanto um gigante; uma pequena república é tão soberana quanto o mais poderoso reino. De uma necessária consequência desta igualdade, o que é permitido para uma nação é permitido para todas [,] e o que é proibido para um é também proibido para todas as nações".

11 LEE, Thomas H. International Law, International Relations Theory and Preemptive War: The Vitaly of Sovereingns Equality Today. Law and Contemporary Problems, volume 67, n. 4, 2004. WALTZER, Michael. Just an Unjust Wars: a Moral Argument with Historical Illustrations. 4a. ed. Basic Books, 2006

12 O Realismo Político das relações internacionais é entendido como uma teoria explicativa 
seria, conforme prescreveu Carl von Clausewitz, “(...) a realização da política por outros meios"13.

O período marcado pelas Guerras Mundiais (1914-1945) consistiu em grande marco na história da humanidade. Pela primeira vez, os Estados adquiriram a capacidade de destruírem totalmente uns aos outros através da Guerra Total: a mobilização de todos os recursos em prol do esforço de guerra aliado ao desenvolvimento de armamentos, cujo poder destrutivo crescia de modo exponencial. ${ }^{14}$

A necessidade de controle da guerra e promoção de uma ordem internacional voltada para a paz representou o objetivo central da Liga das Nações (1919). No entanto, com o reconhecido fracasso ${ }^{15}$ desta iniciativa, a tarefa de promoção da paz e erradicação das guerras ficou a cargo da Organização das Nações Unidas (ONU), instituição internacional criada no cenário do pós-Segunda Guerra Mundial, com amplo respaldo estatal e que inaugurou uma nova era no Direito Internacional, em especial no tocante ao recurso à força armada - cuja proibição passou a ser regra ${ }^{16}$

dos eventos do cenário global. Por fundar suas bases teóricas na filosofia política de Thomas Hobbes e Nicolau Maquiavel, o Realismo Político procura descrever os acontecimentos do ambiente global através de uma análise do equilíbrio de poderes de seus vários atores, que por sua vez encontrar-se-iam imersos em um sistema anárquico - uma vez que não haveria um soberano acima dos Estados capaz de subjugá-los - e onde a busca por sobrevivência e segurança torna-se uma constante. O fim da Guerra Fria é tido como um marco para o Realismo, haja vista que teria havido uma quebra nas relações de poder em nível global. Tal fato explicaria as atuais tendências de reequilíbrio em tais relações: o fortalecimento da União Européia e o crescimento econômico e militar da China seriam indícios da gênese de uma Nova Ordem Internacional BURCHILL, Scott ; LINKLATER, Andrew. (Org) . Theories of International Relations. Palgrave: Macmillian,, 2005). Para um aprofundamento nas teorias políticas das relações internacionais ver BAYLIS, John \& SMITH, Steve (Eds). The Globalization of World Politics. Oxford: OUP, 2007; BURCHILL, Scott e LINKDATER, Andrew et al. Theories of International Relations. Palgrave: Macmillian, 2005; HERZ, John H. Political Realism Revisited. International Studies Quarterly, Vol. 25, No. 2, Symposium in honor of Hans J. Morgenthau, Jun., 1981.

13 CLAUSEWITZ, Carl Von. On war. London: Penguin Books, 1982, p. 88 (tradução livre).

14 CREVELD, Martin Van. Ascensão e declínio do Estado. Trad. São Paulo: Martins Fontes, 2004.

15 Os motivos para este fracasso foram os mais diversos, porém um destes merece destaque: o fato do Senado dos Estados Unidos da América ter declinado de ratificar o Pacto das Ligas das Nações, em 1920. A falta de respaldo de um dos mais importantes Estados da época culminou no desmantelamento da organização. O Pacto Kellogg-Briand de 1928, que proibia o recurso à guerra como meio de solução de controvérsias também fracassou, pois dependia dos mecanismos de aplicação previstos no Pacto da Liga das Nações. BYERS, Michael. A lei da guerra: direito internacional e conflito armado. Rio de Janeiro: Record, 2007.

16 Assim dispõe o Artigo 2 (4) da Carta da ONU: "Todos os Membros deverão evitar em suas relações internacionais a ameaça ou o uso da força contra a integridade territorial ou a independência política de qualquer Estado, ou qualquer outra ação incompatível com os Propósitos das Nações Unidas." 
- e ao desenvolvimento e solidariedade entre os povos. Segundo Ferrajoli, ${ }^{17}$ "A Carta da ONU assinala (...) o nascimento de um novo direito internacional e o fim do velho paradigma - o modelo Vestfália -, que se firmara três séculos antes com o término da guerra européia dos trinta anos."

A Carta da ONU conferiu ao Conselho de Segurança a responsabilidade de manutenção da paz e segurança internacionais. O Capítulo VII da Carta da ONU traz a competência do Conselho de Segurança sobre a aplicação de medidas que não envolvam o emprego de força $\operatorname{armada}{ }^{18}$ para fins de solução de determinada controvérsia. Caso as medidas adotadas revelem-se insuficientes, é competente o Conselho para decidir sobre o recurso à força militar a fim de restaurar a paz e a segurança internacionais. As exceções contempladas à proibição do uso da força seriam, portanto, a autorização do Conselho de Segurança e a legítima defesa frente agressão de outros Estados.

O veto ao ius ad bellum ${ }^{19}$ incondicional foi seguido da aprovação pela Assembléia Geral da ONU da Declaração Universal dos Direitos do Homem em 1948. Tem-se, assim, dois importantes elementos que representam a consolidação de novos objetivos ao Direito Internacional: a limitação do uso da força militar - que até então consistia em um dos alicerces da soberania estatal - e a edificação de valores supraestatais, cuja promoção e respeito são vinculantes a todos os Estados Membros. ${ }^{20}$

Importante entender a construção deste sistema internacional dentro de cenários de hegemonias políticas, econômicas e militares em momentos históricos distintos. O Conselho de Segurança da ONU representa o mundo pós-guerra e a afirmação dos interesses daquelas potências vitoriosas. A hegemonia norte-americana

17 FERRAJOLI, Luigi. A soberania do mundo moderno. Trad. São Paulo: Martins Fontes, 2007 p. 40.

18 Dispõe o Artigo 41 da Carta da ONU: "O Conselho de Segurança decidirá sobre as medidas que, sem envolver o emprego de forças armadas, deverão ser tomadas para tornar efetivas suas decisões e poderá convidar os Membros das Nações Unidas a aplicarem tais medidas. Estas poderão incluir a interrupção completa ou parcial das relações econômicas, dos meios de comunicação ferroviários, marítimos, aéreos, postais, telegráficos, radiofônicos, ou de outra qualquer espécie e o rompimento das relações diplomáticas."

19 O denominado ius ad bellum referem-se às hipóteses nas quais o recurso à força militar para resolução de controvérsias é autorizado pelo Direito Internacional. Por sua vez, o ius in bello refere-se às normas contidas em tratados internacionais destinadas à forma como os conflitos são tratados, com destaque para a proteção das populações civis (Convenção de Genebra de 1949) e à proibição de uso de determinados tipos de armamentos WALZER, Michael. Arguing about war. Yale University Press, 2004. Just an unjust wars: a moral argument with historical illustrations. 4. ed. Basic Books, 2006.

20 BOBBIO, Norberto. A era dos direitos. Tradução de Carlos Nelson Coutinho. Rio de Janeiro: Elsevier, 2004. BYERS, Michael. A lei da guerra: direito internacional e conflito armado. Rio de Janeiro: Record, 2007. FERRAJOLI, Luigi. A soberania do mundo moderno. São Paulo: Martins Fontes, 2007. 
e o reconhecimento de seu aliado mais próximo no mundo capitalista (Inglaterra); uma França que procurava se afirmar como independente no cenário internacional mas claramente envolvida com o projeto europeu (que era norte-americano); uma União Soviética que liderava o mundo socialista e a China como aliada poderosa da Segunda Guerra Mundial no espaço asiático.

Os consensos no pós-guerra não foram construídos de forma igualitária e dialógica. Foram frutos de novas hegemonias que se afirmavam então. A Declaração Universal de Direitos Humanos reflete toda esta reacomodação: trata-se de um texto que reconhece prioritariamente os direitos individuais de origem liberal e decorrente da visão hegemônica norte-americana e européia ocidental. As poucas e discretas menções aos direitos sociais e econômicos decorrem da intervenção do mundo socialista liderado naquela ocasião pela União Soviética.

A Carta das Nações Unidas ainda carrega muito de um Direito Internacional europeu. Desde suas origens, a pretensão civilizatória de uma cultura superior em relação aos selvagens e orientais pautou a construção da ordem internacional e ainda nos dias de hoje sobrevive nos discursos de intervenção humanitária ou em nome da democracia.

\section{A Intervenção Humanitária e o paradigma do Estado de Exceçáo}

Michael Walzer ${ }^{21}$ sistematiza o atual estágio de desenvolvimento do Direito Internacional no que diz respeito ao uso da força armada. Segundo o autor, um "paradigma legal" consolidou-se na sociedade internacional, e seus principais elementos são: (i) a existência de uma sociedade internacional de Estados; (ii) a existência de um Direito que atribui direitos a estes Estados - sobretudo o princípio da integridade territorial e soberania; (iii) a violação destes direitos por outros Estados constitui crime de agressão; (iv) a agressão justifica a defesa legítima do Estado vitimado, de seus aliados ou da comunidade internacional -representada pelo Conselho de Segurança; (v) apenas a agressão justifica a guerra; (vi) o agressor pode ser punido.

A respeito do uso da força militar por parte dos Estados, outras duas exceções não-codificadas podem ter-se desenvolvido nas últimas décadas, segundo Byers: ${ }^{22} \mathrm{O}$ direito de intervir por meios militares para promover ou restabelecer a democracia

\footnotetext{
21 WALZER, Michael. Just an unjust wars: a moral argument with historical illustrations. 4. ed. Basic Books, 2006.

22 BYERS, Michael. A lei da guerra: direito internacional e conflito armado. Rio de Janeiro: Record, 2007.
} 
e o direito de intervir para prevenir graves abusos contra os direitos humanos ou contrários ao Direito Humanitário Internacional, tal como o genocídio.

Estas intervenções marcam a pretensão civilizatória e o pressuposto de desigualdade que fundamenta a visão das potências "ocidentais" diante de outras culturas julgadas inferiores. O discurso de superioridade ocidental é feito de forma mais sofisticada, mas aparece de forma flagrante na imposição de uma democracia ocidental e de direitos humanos ocidentais. O conceito de democracia e direitos humanos que justificam as intervenções é construído na história das potencias ocidentais e imposto de forma naturalizante para todo o mundo. A prática claramente ideológica consiste em tratar como universal o que foi produto de culturas localizadas e com pretensões hegemônicas.

Como ressalta o filósofo e psicanalista Slavoj Zizek:

[...] é necessário interrogar a política humanitária despolitizada dos 'direitos humanos' como ideologia de intervencionismo militar ao serviço de objetivos econômicos e políticos específicos. ${ }^{23}$

Neste sentido, o discurso aparentemente despolitizado dos Direitos Humanos encobre uma visão hegemônica que naturalizada passa a ser universalizada e justifica intervenções militares (humanitárias) de consequências catastróficas para as populações envolvidas.

Estas intervenções militares com fins econômicos são encobertas por discursos humanitários. Importante lembrar que, mesmo as intervenções que visam evitar claras violações de direitos encobrem também interesses econômicos e políticos, muitas vezes inconfessáveis. Estas são as piores uma vez que dificilmente poderíamos negar sua necessidade e justificativa humanitária.

Immanuel Wallernstein ${ }^{24}$ nos lembra que a intervenção humanitária encobrindo interesses econômicos não é nova. Marca a era européia desde seu inicio em 1492: a discussão entre Bartolomeu de las Casas e Sepúlveda inaugura a intervenção militar justificada por razões humanitárias, à época a evangelização dos selvagens. As teses de Sepúlveda prevalecem até nossos dias, substituindo-se o evangelho pelos direitos humanos e a democracia. O número de mortos continua muito grande.

Alguns casos importantes são destacados por especialistas, pois constituiriam os precedentes para a intervenção humanitária unilateral. As intervenções norte-americanas na Granada (1983) e no Panamá25 (1989) são dignas de menção, pois foram

23 ZIZEK, Slavoj. Plaidoyer en faveur de 1'intolerance. Castelnaule-Lez: Editors Climats, 2004, p. 11; Tradução livre.

24 WALLERNSTEIN, Immanuel. O universalismo europeu. São Paulo: Boitempo, 2008.

25 Conforme BYERS, Michael. A lei da guerra: direito internacional e conflito armado. Rio 
as primeiras onde a justificativa principal foi a defesa da democracia. ${ }^{26}$ No caso da invasão do Iraque em 2003, as fundamentações giravam em torno da deposição de um governo tirânico, o estabelecimento de um regime democrático no país e do direito de legítima defesa da potência invasora. ${ }^{27}$

Alguns internacionalistas não reconhecem uma prática estatal favorável à intervenção humanitária, não havendo que se falar no desenvolvimento de um jus cogens a este respeito no Direito Internacional consuetudinário. ${ }^{28}$ Esta vem sendo a posição dominante no sistema jurídico global, pois legitima o paradigma legal estabelecido:

Governos e exércitos envolvidos em massacres são amplamente identificados como governos e exércitos criminosos (eles são culpados de acordo com o Código de Nuremberg por 'crimes contra a humanidade'). Portanto a intervenção humanitária se aproxima muito mais do que qualquer outra espécie de intervenção que comumente compreendemos, nas sociedades domésticas, como reforço da lei ou trabalho da polícia. Ao mesmo tempo, no entanto, a intervenção requer atravessar uma fronteira internacional, e tal travessia é descartada pelo paradigma legal - a menos que seja autorizada [...] pela sociedade de nações. ${ }^{29}$

A competência do Conselho de Segurança para autorizar o uso da força armada e de tomar medidas aptas a restaurar a paz e a segurança não raras vezes entra em

de Janeiro: Record, 2007, p. 113 explica: "De duas maneiras o governo americano invocou a democracia para tentar justificar a invasão do Panamá: como exercício do direito de agir em caráter unilateral para promover a democracia em outros países e a título de ajuda a um chefe de Estado democraticamente eleito, Guilhermo Endara, que concordava ostensivamente com a iniciativa." O autor esclarece ainda que o convite de um governo para que outro interfira militarmente como forma de ajudar a restabelecer a ordem interna é um costume plenamente aceito no Direito Internacional.

26 BYERS, Michael. A lei da guerra: direito internacional e conflito armado. Rio de Janeiro: Record, 2007.

27 A Estratégia de Defesa Nacional de setembro de 2002 - conjunto de objetivos e orientações adotados pelos Estados Unidos após os ataques de 11 de Setembro de 2001 no tocante à política externa - comprova a disposição de Washington de contrair qualquer norma de Direito Internacional que possa representar uma ameaça à segurança nacional. No entanto, o documento vai mais além, contemplando agressivas políticas de imposição de valores liberaldemocráticos e fortalecimento do sistema capitalista mundial: "O Propósito da nossa nação sempre foi mais amplo que nossa defesa nacional. Nós lutamos, como sempre lutamos, por uma paz justa - uma paz que favoreça a liberdade. Nós defenderemos a paz contra as ameaças de terroristas e tiranos. Nós preservaremos a paz através da construção de boas relações entre as grandes nações. E nós estenderemos a paz pelo encorajamento de sociedades livres e abertas em todos os continentes." Tradução livre THE NATIONAL SECURITY STRATEGY OF THE UNITED STATES OF AMERICA, 2002. Disponível em: <http://www.au.af.mil/au/ awc/awcgate/nss/nss_sep2002.pdf>. Acesso em: 5 abr. 2007.

28 BYERS, Michael. A lei da guerra: direito internacional e conflito armado. Rio de Janeiro: Record, 2007.

29 WALZER, Michael. Just an unjust wars: a moral argument with historical illustrations. 4. ed. Basic Books, 2006, p. 106. Grifo nosso. Tradução livre. 
contraste com os interesses dos membros permanentes do Conselho. O poder de veto de destes membros corresponde, na prática, à redução da atuação do Conselho de Segurança, uma vez que se torna dependente de interesses domésticos.

Os Estados fazem uso de um vasto arsenal de discursos para evitar tratar as graves violações de Direitos Humanos com o comprometimento devido. De um modo geral, as justificativas apresentadas giram em torno da proibição legal e da necessidade de respeitar os demais princípios basilares das relações interestatais. No entanto, os argumentos jurídicos são apenas uma fração da complexidade da matéria. ${ }^{30}$ Eric Heinze, ao comparar os discursos políticos seguidos por Washington nas crises humanitárias em Ruanda e no Sudão, ressalta que pressões domésticas, de um lado, e a (in)existência de interesses geopolíticos ou econômicos ${ }^{31}$ em relação à região em questão, são elementos recorrentes na retórica de negação das graves atrocidades em curso. Outros membros ${ }^{32}$ do Conselho de Segurança agem da mesma forma, reduzindo drasticamente as possibilidades de coordenação de esforços em torno de objetivos comuns.

A justificação da impossibilidade de intervenção humanitária por parte dos Estados reforça e legitima o paradigma legal consolidado há três séculos. Deste modo, o Direito Internacional necessita de instrumentos aptos a fomentar um discurso favorável e emancipador em favor da proteção dos Direitos Humanos nestas hipóteses extremas. A motivação para novas alternativas pode estar - assim acreditamos - na compreensão de uma prática que vem se consolidando nas últimas décadas: o paradigma do Estado de Exceção.

Giorgio Agamben ${ }^{33}$ descreve a tendência contemporânea da abolição gradual de direitos e liberdades individuais em prol do fortalecimento do poder executivo como um novo paradigma de governo representado pela constitucionalização do Estado de Exceção: "[...] conforme uma tendência em todas as democracias ocidentais, a declaração do Estado de Exceção é progressivamente substituída por uma generalização sem

30 FERRA JOLI, Luigi. A soberania do mundo moderno. São Paulo: Martins Fontes, 2007

31 Os EUA firmaram diversos acordos de combate ao terrorismo com o governo sudanês, e atualmente estão engajados nas negociações do processo de paz para a guerra civil entre as regiões norte e sul do país. A desastrosa campanha na Somália (1993) e as ações militares no Afeganistão e Iraque reforçam o desinteresse para com as violações de Direitos Humanos em curso em Darfur.

32 BYERS, Michael A lei da guerra: direito internacional e conflito armado. Rio de Janeiro: Record, 2007 explica que a China vem fazendo uso de seu poder de veto para frear iniciativas sérias para por fim à crise humanitária em Darfur, uma vez que uma intervenção humanitária ampla prejudicaria contratos firmados com o governo sudanês para a exploração de petróleo e outros recursos naturais.

33 AGAMBEN, Giorgio. Estado de exceção. São Paulo: Boitempo, 2004. 
precedentes do paradigma da segurança como técnica moral de governo.”34

Sob o argumento de necessidade de resposta a uma determinada situação de emergência - em geral política, militar e econômica - os governos lançam-se em uma série de medidas de cunho totalitário, procurando justificar tais medidas sob o argumento da proteção do Estado e de suas instituições. Estas justificativas pretendem conferir caráter jurídico a situações não-contempladas pela normalidade da prática constitucional:

O estado de exceção é, nesse sentido, a abertura de um espaço em que aplicação e norma mostram sua separação e em que uma pura forçade-lei realiza (isto é, aplica desaplicando) uma norma cuja aplicação foi suspensa. Desse modo, a união impossível entre norma e realidade, e conseqüente constituição do âmbito da norma, é operada sob a forma de exceção, isto é, pelo pressuposto de sua relação. Isso significa que, para aplicar uma norma, é necessário, em última análise, suspender sua aplicação, produzir uma exceção. Em todos os casos, o estado de exceşão marca um patamar onde lógica e práxis se indeterminam e onde uma pura violência sem logos pretende realizar um enunciado sem nenbuma referência real. ${ }^{35}$

O Estado de Exceção não pode ser considerado um fenômeno recente. A tendência de supressão de quaisquer direitos individuais existentes e instituição de um Estado de Direito sem Direito consiste em uma história ${ }^{36}$ que vem sendo contada há séculos e que - infelizmente - parece estar longe de terminar.

O que difere o Estado de Exceção contemporâneo do seu equivalente mais antigo é, a uma, a capacidade de mobilização da sociedade civil - nos planos nacional e internacional - e, a duas, a ampla divulgação pelos meios de comunicação dos casos onde a supressão dos direitos e institucionalização da barbárie atinge níveis intoleráveis. Deste modo, no âmbito do Direito Internacional, o paradigma do Estado de Excȩão guarda forte liame com o uso da força militar pelos Estados e pela sociedade internacional, uma vez que as graves violações de direitos humanos a que se referem os defensores da intervenção humanitária ${ }^{37}$ constituem a manifestação máxima do Estado de Excę̧ão.

34 AGAMBEN, Giorgio. Estado de exceção. São Paulo: Boitempo, 2004, p.27

35 AGAMBEN, Giorgio. Estado de exceção. São Paulo: Boitempo, 2004, p. 63. Grifo nosso.

36 AGAMBEN, Giorgio. Estado de exceção. São Paulo: Boitempo, 2004 indica a França revolucionária do fim do século XVIII na origem deste fenômeno. Espalhou-se por outros Estados europeus, como a Alemanha, a Suíça e a Itália, para consolidar-se como paradigma de governo no eclodir da Primeira Guerra Mundial. Na obra O Estado de Exceşão, o autor apresenta o importante debate travado entre dois estudiosos do Estado de Exceção contemporâneo: Carl Schmitt e Walter Benjamin.

37 Remetemos a importante trabalho sobre o tema, na qual o autor propõe que Estados da comunidade internacional elaborem um tratado para fins de intervenção humanitária independente do Conselho de Segurança ou da ONU. Nesse sentido, ver: CRITCHLOW, George A. Stopping genocide through international agreement when the Security Council fails to act. 


\section{Conclusão}

A prevalência dos Direitos Humanos - consolidados em importantes tratados e convenções -, assim como o desenvolvimento de mecanismos de promoção e defesa destes direitos no plano internacional - por meio de agências internacionais vinculadas à ONU, organizações não-governamentais e sistemas regionais de proteção - apontam para uma responsabilidade da sociedade internacional em casos de graves violações dos referidos direitos.

Os atuais mecanismos de promoção da paz e segurança internacionais foram formulados sobre uma concepção de Direito Internacional na qual os Estados são, em última análise, os principais protagonistas no cenário global. As violações em massa de direitos humanos por parte de governos refletem a consolidação de um Estado de Exceção que suprime direitos e liberdades individuais e que se propõe a legitimar as mais variadas práticas totalitárias.

A emergência deste paradigma de governo muitas vezes se dá ao custo de profundas violações aos Direitos Humanos. A proteção destes direitos, nestas hipóteses extremas, não pode ficar a cabo exclusivamente do juízo de alguns Estados, seus interesses nacionais e ideologias justificadoras da barbárie. O caminho parece ser a superação de dogmas seculares em prol de uma consciência coletiva e emancipadora.

Georgetown Journal of International Law, volume 40, número 1, p. 311-343, 2009. 


\section{Referências Bibliográficas}

AFONSO, Henrique Weil. Unidade e fragmentação do direito internacional: o papel dos direitos humanos como elemento unificador. Revista Eletrônica de Direito Internacional, v. 4, p. 53-90, 2009.

AGAMBEN, Giorgio. Estado de exceção. São Paulo: Boitempo, 2004.

BOBBIO, Norberto. A era dos direitos. Tradução de Carlos Nelson Coutinho. Rio de Janeiro: Elsevier, 2004.

BURCHILL, Scott; LINKLATER, Andrew (Org.). Theories of international relations. Palgrave: Macmillian, 2005.

BYERS, Michael. A lei da guerra: direito internacional e conflito armado. Rio de Janeiro: Record, 2007.

CLAUSEWITZ, Carl von. On war. London: Penguin Books, 1982.

CREVELD, Martin van. Ascensão e declínio do estado. São Paulo: Martins Fontes, 2004.

CRITCHLOW, George A. Stopping genocide through international agreement when the Security Council fails to act. Georgetown Journal of International Law, v. 40, n. 1, p. 311-343, 2009.

FERRAJOLI, Luigi. A soberania no mundo moderno. São Paulo: Martins Fontes, 2007.

HART, H.L.A. The concept of law. Oxford: Clarendon Press, 1961.

HEINZE, Eric A. The rhetoric of genocide in U.S. foreign policy: Rwanda and Darfur compared. Political Science Quarterly, v. 122, n. 3, p. 359-383, 2007.

HOBSBAWM, Eric J. A era dos extremos. São Paulo: Cia das Letras, 2001.

KELSEN, Hans. Teoria pura do direito. São Paulo: Martins Fontes, 2006.

LEE, Thomas H. International law, international relations theory and preemptive war: the vitality of sovereign equality today". Law and Contemporary Problems, v. 67, n. 4, 2004.

MAGALHÃES, José Luiz Quadros de. Identidades e identificações: da possibilidade de construção de uma ética universal. Veredas do Direito, v. 5, n. 9/10, jan.-dez. 2008, p. 45-61.

ROSENNE, Sh. Recueil des cours. Tome 291 de La collection. The Hague: Martinus Nijhoff Publishers, 2002.

SANTOS, Boaventura de Sousa. Uma concepção multicultural de direitos humanos. Lua Nova. Revista de Cultura e Política, n. 39, p. 105-124, 1997.

WALLERNSTEIN, Immanuel. O universalismo europeu. São Paulo: Boitempo, 2008.

WALZER, Michael. Arguing about war. Yale University Press, 2004.

. Just and unjust wars: a moral argument with historical illustrations. 4. ed. Basic Books, 2006.

ZIZEK, Slavoj. Plaidoyer en faveur de l'intolerance. Castelnau-le-Lez: Editions Climats 2004. 